\title{
ESTUDO DA INFLUÊNCIA DA TEMPERATURA DE PIRÓLISE NO BIOCARVÃO OBTIDO A PARTIR DO MESOCARPO DO COCO (COCOS NUCIFERA L.)
}

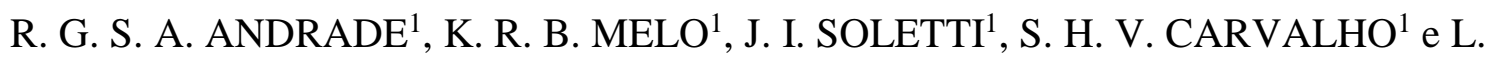 \\ MEILI $^{1}$ \\ ${ }^{1}$ Universidade Federal de Alagoas, Centro de Tecnologia (CTEC) \\ E-mail para contato: ragabiandrade@gmail.com
}

\begin{abstract}
RESUMO - A pirólise é o processo de degradação termoquímica da matéria-prima na ausência total de oxidante, do qual se obtém três produtos, biocarvão, bio-óleo e gases incondensáveis. As proporções e características desses produtos variam com as condições operacionais utilizadas no processo. O carvão pode ser chamado de biocarvão (biochar) e adicionado ao solo para elevar o nível de fertilidade através da retenção de nutrientes nos poros presentes no carvão. O presente trabalho avaliou as quantidades e características físico-químicas dos biocarvões obtidos a partir do mesocarpo do coco, com variação da temperatura final de operação, mantendo fixas as demais variáveis. As temperaturas foram de $400{ }^{\circ} \mathrm{C}, 500{ }^{\circ} \mathrm{C}, 600{ }^{\circ} \mathrm{C}$ e $700{ }^{\circ} \mathrm{C}$, a taxa de aquecimento foi de $10^{\circ} \mathrm{C} / \mathrm{min}$, com tempo de residência de 120 minutos. Os carvões foram caracterizados através do MEV, pH e FT-IR. Os dados obtidos indicaram que o rendimento sólido decai com o aumento da temperatura final, enquanto o rendimento líquido cresce. A análise de microscopia mostrou que as partículas que constituem os carvões são irregulares e em temperaturas mais elevadas possuem estruturas porosas não homogêneas. Os carvões estudados apresentaram características alcalinas, que aumentaram com a elevação da temperatura, além de possuírem composição química semelhante, comprovado pela análise de FT-IR. Desse modo, os carvões analisados possuem características que podem ser benéficas para o tratamento do solo.
\end{abstract}

\section{INTRODUÇÃO}

\subsection{Pirólise}

A pirólise envolve o aquecimento da biomassa na ausência de um agente oxidante qualquer, utilizando uma taxa de aquecimento específica até uma temperatura máxima onde o sistema permanece durante um tempo específico, conhecido como tempo de residência. Ao final do processo são obtidos três produtos, líquido (bio-óleo), sólido (carvão) e gases (óxidos de carbono, água, hidrogênio, hidrocarbonetos e diversos tipos de moléculas orgânicas). $\mathrm{O}$ rendimento e a composição dos produtos são altamente dependentes das condições do processo (temperatura, tempo de residência, taxa de aquecimento) e das características físico-químicas da própria biomassa (Basu, 2010). 


\subsection{Biocarvão}

O carvão quando adicionado ao solo objetivando melhorar suas propriedades físicas, químicas e biológicas é chamado de biocarvão ou biochar. É composto pela matéria-prima carbonizada, material volátil, cinzas e água (Kookana et al., 2011). Esse produto apresenta como característica importante a presença de poros em sua estrutura, que atuam na estocagem dos nutrientes do solo, sendo liberados em épocas de escassez. Pode ser obtido a partir de uma grande variedade de matéria-prima, sendo o coco - da- baía (cocos nucifera L.) o material de estudo do presente trabalho.

O coco possui uma parte fibrosa, que envolve o endocarpo, denominada mesocarpo, conhecida popularmente como fibra do coco. Segundo Silva (2006), são materiais lignocelulósicos caracterizados pela sua dureza e durabilidade atribuída ao alto teor de lignina, quando comparadas com outras fibras naturais. Por apresentar uma baixa taxa de degradação, é necessário reduzir a quantidade de resíduos gerados através do seu aproveitamento. Desse modo, essa matéria-prima foi utilizada para realização das pirólises.

\section{METODOLOGIA}

As pirólises foram realizadas em uma unidade composta por um forno tubular JUNG modelo LT6 2010, com controlador de temperatura, taxa de aquecimento e tempo de residência. O forno possui ligação direta com um sistema formado por 3 condensadores, sendo dois deles em série e o outro em paralelo, conectados a 2 kitasssatos para a coleta do bio- óleo, resfriados por um banho termostatizado modelo TE-184, e uma bomba de vácuo promove a ausência de oxidante no meio. As temperaturas de operação das pirólises foram de $400{ }^{\circ} \mathrm{C}, 500{ }^{\circ} \mathrm{C}, 600{ }^{\circ} \mathrm{C}$ e $700{ }^{\circ} \mathrm{C}$, a taxa de aquecimento foi de $10^{\circ} \mathrm{C} / \mathrm{min}$, com tempo de residência de 120 minutos e temperatura do banho de $3{ }^{\circ} \mathrm{C}$. A biomassa utilizada foi previamente seca ao sol, e a massa inicial foi de $80,0 \mathrm{~g}$ em cada pirólise. Após a obtenção dos carvões foram realizadas as análises de MEV, pH e FT-IR.

$\mathrm{Na}$ análise de microscopia eletrônica de varredura (MEV) utilizou-se o equipamento Shimadzu, modelo SSX-550 Superscan. As amostras de carvão foram metalizadas com alvo de ouro (corrente de $10 \mathrm{~mA}$ ) durante 6 minutos. O metalizador utilizado foi o SanyuElectron, modelo QuickCoater SC-701.A análise foi realizada no Laboratório de Microscopia de Varredura Eletrônica (SEM) do Grupo de Óptica e Nanoscopia da Universidade Federal de Alagoas (UFAL).

Para a análise de $\mathrm{pH}$ foi pesado $1,0 \mathrm{~g}$ dos carvões macerados de cada temperatura e adicionados $20 \mathrm{~mL}$ de água deionizada. A análise foi realizada em triplicata. As amostras ficaram em uma Incubadora SHAKER Solab modelo SL222 durante uma hora e meia, com rotação de 100 rpm. Depois o pH foi medido com um pHmetro Marconi modelo PA 200.

A espectroscopia no infravermelho via transformada de Fourier (FT-IR) foi realizada com o equipamento FT-IR NICOLET modelo iS 10 no Laboratório de Tecnologia de Nanosistemas Carreadores de Substâncias Ativas (TecNano) na Universidade Federal de Alagoas (UFAL) e utilizou o método de transmitância, com pastilhas de $\mathrm{KBr}$ com $20 \mathrm{mg}$ de amostra e $200 \mathrm{mg}$ de $\mathrm{KBr}$, com número de onda entre $4000 \mathrm{~cm}^{-1}$ e $400 \mathrm{~cm}^{-1}$ e resolução $4 \mathrm{~cm}^{1}$. 


\section{RESULTADOS}

\subsection{Rendimentos dos Produtos}

Para a determinação dos rendimentos dos produtos da pirólise foram utilizadas as Equações 1, 2 e 3 e os resultados estão expostos na Tabela 1.

$$
\begin{aligned}
& R_{\text {sólido }}=\frac{m_{\text {carvão }}}{m_{\text {inicial }}} \times 100 \\
& R_{\text {líquido }}=\frac{m_{\text {óleo }}}{m_{\text {inicial }}} \times 100 \\
& R_{\text {gasoso }}=100-\left(R_{\text {sólido }}+R_{\text {líquido }}\right)
\end{aligned}
$$

Tabela 1 - Rendimentos em função das temperaturas

\begin{tabular}{|c|c|c|c|}
\hline $\begin{array}{c}\text { Temperatura } \\
\left({ }^{\circ} \mathrm{C}\right)\end{array}$ & $\begin{array}{c}\text { Rendimento } \\
\text { sólido }(\%)\end{array}$ & $\begin{array}{c}\text { Rendimento } \\
\text { líquido }(\%)\end{array}$ & $\begin{array}{c}\text { Rendimento } \\
\text { gasoso }(\%)\end{array}$ \\
\hline \hline 400 & 43,75 & 28,25 & 28,00 \\
\hline 500 & 39,00 & 29,63 & 31,37 \\
\hline 600 & 38,25 & 31,63 & 30,12 \\
\hline 700 & 33,25 & 35,50 & 31,25 \\
\hline
\end{tabular}

A análise dos dados expostos na Tabela 1 permite concluir que o aumento da temperatura da pirólise reduz o rendimento sólido (biocarvão) e aumenta o rendimento líquido (bio-óleo). Com relação ao rendimento gasoso, os valores variam de acordo com os outros rendimentos, por ser obtido a partir do balanço de massa global dos produtos. Além disso, os carvões produzidos em temperaturas mais elevadas $\left(600{ }^{\circ} \mathrm{C}\right.$ e $\left.700{ }^{\circ} \mathrm{C}\right)$ apresentaram coloração mais homogênea quando comparados aos carvões de $400{ }^{\circ} \mathrm{C}$ e $500{ }^{\circ} \mathrm{C}$, indicando que a biomassa foi convertida de maneira mais eficiente nas temperaturas em questão.

\subsection{Caracterizações dos Carvões}

Os carvões das quatro temperaturas foram caracterizados quanto à morfologia, potencial hidrogeniônico, e espectroscopia.

- $\quad$ Microscopia Eletrônica de Varredura (MEV)

A partir das imagens obtidas em diferentes resoluções (Figuras 1 a 6) observou- se que os carvões apresentaram morfologia variada, como irregularidade na forma e no tamanho das partículas. No carvão de $400{ }^{\circ} \mathrm{C}$ não é possível visualizar a existência de poros na resolução analisada (Figura 1), indicando que nessa temperatura o carvão obtido ainda não foi o adequado. As demais temperaturas apresentaram poros de formatos não homogêneos em sua superfície (Figuras 2,3 e 4), característica importante dos carvões. Além disso, aumentando a resolução observam- se estruturas rugosas e lamelares (Figuras 5 e 6), com microporos na superfície. 
Figura $1-400^{\circ} \mathrm{C} 500 \mathrm{X} . \quad$ Figura $2-500{ }^{\circ} \mathrm{C} 500 \mathrm{X} . \quad$ Figura $3-600{ }^{\circ} \mathrm{C} 500 \mathrm{X}$.

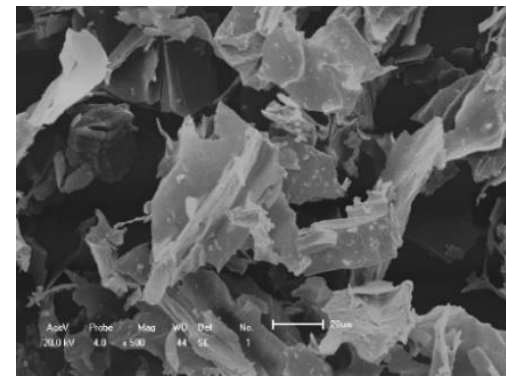

Figura $4-700{ }^{\circ} \mathrm{C} 500 \mathrm{X}$.
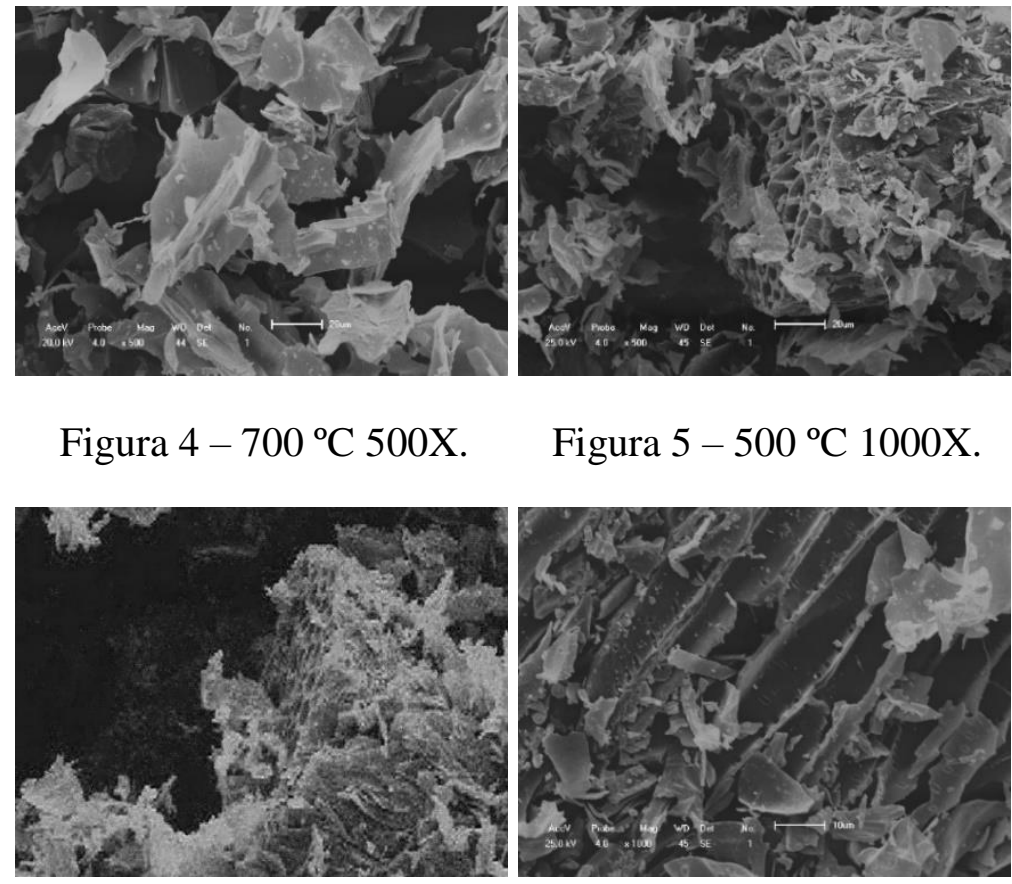

Figura $5-500{ }^{\circ} \mathrm{C} 1000 \mathrm{X}$.

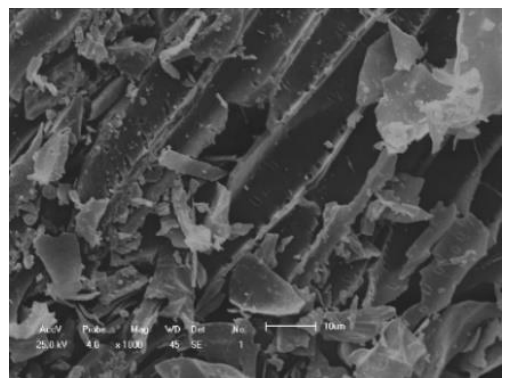

- $\mathrm{pH}$

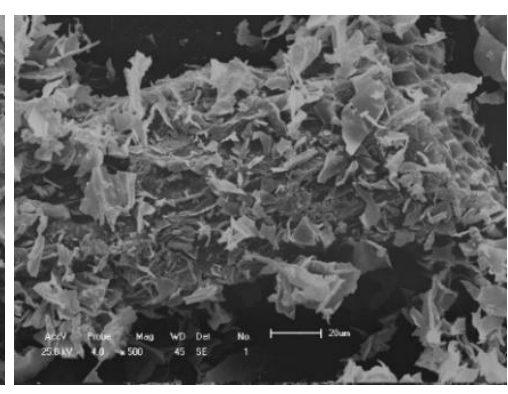

Os dados de $\mathrm{pH}$ obtidos podem ser visualizados na Tabela 2 a seguir. Os valores de $\mathrm{pH}$ aumentaram gradualmente com a elevação da temperatura até os carvões de $600{ }^{\circ} \mathrm{C}$, apresentando um leve decréscimo nos carvões de $700{ }^{\circ} \mathrm{C}$. Mesmo com a diminuição do pH, todos os carvões analisados apresentaram características básicas, com poucos desvios da média, indicando resultados confiáveis com base em dados encontrados na literatura.

Tabela 2 - Valores de $\mathrm{pH}$ dos carvões a diferentes temperaturas

\begin{tabular}{|c|c|c|c|c|}
\hline $\begin{array}{c}\text { Temperatura } \\
\left({ }^{\circ} \mathrm{C}\right)\end{array}$ & 400 & 500 & 600 & 700 \\
\hline \hline Amostra 1 & 8,62 & 9,29 & 9,63 & 9,58 \\
\hline Amostra 2 & 8,68 & 9,25 & 9,60 & 9,52 \\
\hline Amostra 3 & 8,66 & 9,24 & 9,64 & 9,53 \\
\hline Média & $8,65 \pm 0,03$ & $9,26 \pm 0,02$ & $9,62 \pm 0,02$ & $9,54 \pm 0,03$ \\
\hline
\end{tabular}

- $\quad$ FT-IR

As curvas obtidas estão expostas na Figura 7. O comportamento destas comprovou a composição esperada para os carvões, determinada através dos grupos químicos presentes. As curvas de todos os carvões foram semelhantes entre sim, sendo o pico em torno de $3400 \mathrm{~cm}^{-1}$ devido a vibrações de alongamentos $\mathrm{O}-\mathrm{H}$ em grupos hidroxila, enquanto na região próxima a $1700 \mathrm{~cm}^{-1}$ está presente o pico pelo alongamento das ligações $\mathrm{C}=\mathrm{O}$ em cetonas e carbonilas. Em torno de $1000 \mathrm{~cm}^{-1}$ ocorre o alongamento e a deformação das ligações $\mathrm{C}-\mathrm{O}$ e entre $700 \mathrm{~cm}^{-1} \mathrm{e}$ $400 \mathrm{~cm}^{-1}$ ocorre o alongamento das ligações C-C (Choudhury et al., 2014). 
Figura 7 - FT-IR da fibra do coco.

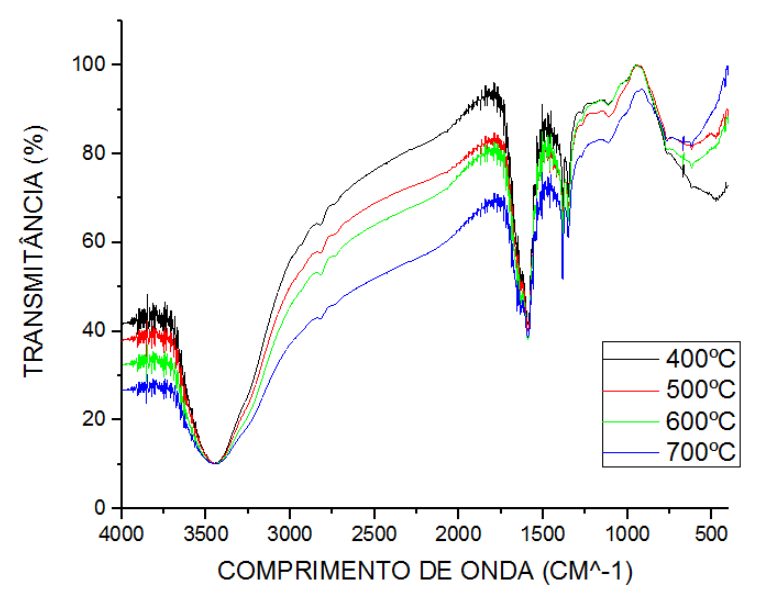

\title{
4. CONCLUSÕES
}

Os biocarvões apresentam variações quantitativas e qualitativas de acordo com as condições operacionais utilizadas no processo de pirólise. Quanto maior a temperatura final utilizada, menor será o rendimento de biocarvão e maior será o rendimento de bio-óleo. Essa variável também afeta a morfologia do carvão produzido, a partir de $500{ }^{\circ} \mathrm{C}$ foram observados poros bem definidos, de tamanhos variados. Todos os carvões apresentaram partículas de tamanhos e formas não homogêneas.

Os carvões produzidos possuem natureza básica, apresentando maiores valores com o aumento de temperatura. Essa semelhança em sua composição foi comprovada na análise de FT-IR, pois as curvas obtidas para diferentes temperaturas foram muito semelhantes, indicando que a variação de temperatura analisada não altera fortemente sua composição, pois apresentam praticamente os mesmos grupos químicos, afetando de forma mais significativa sua morfologia. Logo, os carvões analisados apresentam potencial para atuar no aumento da fertilidade do solo e na redução da sua acidez, por possuir natureza alcalina. No entanto, são necessários estudos mais aprofundados para especificar as melhores condições para a utilização do biocarvão.

\section{NOMENCLATURA}

\author{
m carvão - massa de carvão obtida na pirólise \\ móleo - massa de bio-óleo obtida na pirólise \\ $\mathrm{m}_{\text {inicial }}$-massa de biomassa inicial \\ $\mathrm{R}_{\text {gasoso }}$ - Rendimento gasoso \\ $\mathrm{R}_{\text {líquido }}$ - Rendimento líquido \\ $\mathrm{R}_{\text {sólido }}$ - Rendimento sólido
}




\section{Congresso Brasileiro de Engenharia Química \\ em Iniciação Científica \\ UFSCar - São Carlos - SP

\section{REFERÊNCIAS}

BASU, P. Biomass Gasification and Pyrolysis: Practical Design and Theory. Oxford: Elsevier, 2010. 364 p.

CHOUDHURY; DEV, N.; SINGH, C. R.; THALLADA, B.; RUPAM, K. Pyrolysis of jute effect of reaction parameters and analysis of products. The Journal of material cycles and waste managment, vol. 16, p. 449-459, 2014.

KOOKANA, R.S; SARMAH, A.K; ZWIETEN, L.; VAN; KRULL, E.; SINGH, B; Biochar application to soil: agronomic and environmental benefits and unintended consequences. Advances in Agronomy, San Diego, v. 112, p. 103-143, 2011.

SILVA, R. V.; SPINELLI, D.; BOSE FILHO, W. W.; CLARO NETO, S.; CHIERICE, G. O.; TARPANI, J. R. Fracture toughness of natural bers/castor oil polyurethane composites. Composites Science Tecnology, Barking, v. 66, n. 10, p. 1328-1335, 2006. 